\title{
HEART AND ANTERIOR ARTERIES IN MONSTERS OF THE DICEPHALUS GROUP; A COMPARATIVE STUDY OF COSMOBIA. ${ }^{1}$
}

\author{
BY \\ MABEL BISHOP, \\ Fellow in Zoölogy, Smith College, 1907-1908. \\ With 7 Prates and 5 Text Figures.
}

I. Introduction.

OUTLINe.

Investigation of monsters, hitherto descriptive.

Comparisons now needed.

Definition of "Cosmobia."

Purpose of the present investigation.

II. Material studied.

A. Young normal pig, lamb, and turtle.

B. The following terata:-

(a) Pig fotus at term, Teras XII.

(b) Pig embryo, $22 \mathrm{~mm}$., Teras I.

(c) Dicephalous lamb, 3 to 4 weeks old, Teras $\mathrm{XV}$.

(d) Two-headed turtle, just hatched, Teras XX.

III. General description of each Teras, including comparison with human monsters of similar type as represented in well-known atlases.

IV. Detailed description of the Heart and Anterior Arteries in each Teras.

${ }^{2} \mathrm{~A}$ thesis submitted to the Faculty of Smith College in partial fulfilment of the requirement for the degree of Master of Arts, May 20, 1908.

The Ammican Jolnnal of Anatomy,-ron. Vilt, Xo. 4. 
(1) In Teras XII.

(a) Heart-Comparison with normal.

(b) Anterior Arteries-Comparison with normal. $x$-Arteries of the outer sides of the two components.

$\mathrm{xx}$-Arteries of the inner (median) sides of the two components.

(2) In Teras I--Reserved for separate investigation.

(3) In Teras XV.

(a) Heart-Comparison with normal.

(b) Anterior Arteries-Comparison with normal. $x$-Arteries of the outer sides of the two heads.

$x x$-Arteries of the inner (median) sides of the two heads.

(4) In Teras XX.

(a) Heart-Comparison with normal.

(b) Anterior Arteries-Comparison with normal.

$x$-Arteries of the outer sides of the two heads.

$x x$-Arteries of the inner (median) sides of the two heads.

V. Comparisons of the Heart and Anterior Arteries of the Cosmobia.

(a) Teras XV with XII.

(b) Teras XX with XV.

VI. Speculations concerning the formation of the actual conditions in the Cosmobia.

VII. The establishment of a single cosmobiotic series between normal individuals and duplicate twins.

Teratological literature is prolific with descriptive investigations of individual monsters, but prior to the present study very little has been recorded of COMPARISONS of monsters. ${ }^{2}$ While a record of single cases

\footnotetext{
${ }^{2}$ Wenzel Gruber in 1815 cited certain differences of internal anatomy in two cases of "Thoracogastrodidymus," but his comparisons were few in number and rery general. In $1901 \mathrm{~K}$. H. Johnson compared "Axial Bifurcation" in chirteen or more two-headed suakes. These and certain obvious comparisons of skeletons, such as illustrated in well-known atlases, seem to be about all the work that has been done in this line.
} 
is obviously essential it means the accumulation of a mass of unrelated facts, each fact interesting in itself, but valuable only as it contributes to a fuller understanding of the subject as a whole.

H. H. Wilder ${ }^{3}$ has pointed out that a certain class of monsters may pass through a development as natural, orderly, and symmetrical as a normal individual "in accordance with the laws of growth inherent in the organism." He has granted that the monsters in this class are unusual, "abnormal" in the root meaning of the word, but they are neither deformities nor malformations, and should be carefully distinguished from deformed or pathological anomalies. This distinction Wilder has made, and he has shown that the class includes "forms with less and those with more than the normal number of parts," and that it suggests an almost complete single series of symmetrical anomalies lying upon either side of and including normal beings. If this be true, it further suggests a progressive relationship between defective and dicephalous monsters.

This separation of unusual from deformed or pathological monsters necessitates a distinct term for the former, one which is broad enough to include also normal beings. Wilder has proposed the name CosmoBION (plural COSMOBIA) meaning "an orderly living being," and since he has explained the term in full I shall adopt its use without further consideration.

The verity of his assumption that there is, "First, a distinction between the symmetrical anomalies on either side of a normal being and the various sorts of deformed and misshapen monsters resulting from abnormal conditions during development, and, second, the possibility of considering in a single series both those forms with less and those with more than the normal number of parts, including also normal beings," can be proved only by the investigation of the structure of all kinds of cosmobia, and by careful comparisons of those that belong in the same series. Hence, what are needed now more than descriptive investigations are comparative investigations of material already at hand.

This paper is presented, therefore, as the first comparative study of cosmobia with the hope that it may stimulate further research in this field. I shall endeavor to show that the four cases of monsters, studied in the details of their internal anatomy, represent four progressive stages between normal creatures and complete, symmetrical duplicity,

${ }^{3}$ Wilder, H. H., Morphology of Cosmobia, this Journal, 1908, p. 355. 
or, in other words, they represent four successive stages in the cosmobiotic series which leads through dicephali to the Tocci group, and thence through ischiopagy to duplicate twins [Wilder, 1904, series A and D].4 The material studied consists of :-

1. A normal pig, very young, umbilical cord still attached. [Obtained from F. D. Lambert.]

2. A normal lamb, and a normal turtle (Chrysemmys picta).

3. Pig fotus, probably at term, diprosopus triophthalmus; Teras XII of H. H. Wilder's collection. [Obtained from B. G. Wilder.]

4. Pig embryo $22 \mathrm{~mm}$. long, diprosopus tetrophthalmus; Teras I of H. H. Wilder's collection. [Obtained from F. D. Lambert.]

5. Dicephalous lamb, three to four weeks old, born at Ludlowville, New York; Teras XV of H. H. Wilder's collection. [Obtained from B. G. Wilder.]

6. 'Two-headed turtle, Chrysemmys picta, just hatched; Teras XX of H. II. Wilder's collection. [Obtained from A. D. Mead.]

The last four specimens are listed in the order of their sequence in the cosmobiotic series, the simplest stage first. For the sake of convenience I shall hereafter refer to these according to the number in Professor Wilder's list, as given above.

I am directly indebted to Professor Wilder for this material, and indirectly to the gentlemen whose names are bracketed. To all of them I desire to express my thanks for their contributions of material, which have made the present investigation possible.

Teras XII is a pig fœtus delivered at term, perfectly normal in appearance, except in the head region. The length of the animal from the tip of either snout along the mid-dorsal line to root of tail is 36.5 $\mathrm{cm}$. (tail $-7.5 \mathrm{~cm}$.). The condition in the head region places the creature at once in that class of anomalies which is more than one but less than two individuals (monstra in excessu), and represents the first stage beyond the normal in the cosmobiotic series already defined.

For simplicity in this and in the other terata, I shall designate the right head, or portion of head, as "Component A," and the left as "Component B."

Teras XII resembles closely in external doubling the human diprosopi triophthalmi of Förster [Tafel I, Fig. 1], Ahlfeld [Tafel IX, Fig. 1],

${ }^{4}$ Wilder, H. H., Duplicate Twins and Double Monsters, Amer. Jotr. of Anat., Vol. III, 1904. 
and Hirst and Piersol [page 14\%, Fig. 72]. The human face is so short as compared with the elongated faces of the monsters under consideration that at first sight, perhaps, the similarity is not striking, but a moment's consideration will verify the likeness. In my specimen the two snouts are quite separate, the distance between their tips being $8 \check{\mathrm{mm}}$. Both appear normal, well developed and of equal size. Two normal external ears are present, but there is no indication of a median pinna. Within the mouth cavity of each component is a fully developed tongue and several teeth. Protruding from the inner lateral side of the mouth of each component is a short papilla-like protuberance whice curves slightly upward over the upper jaw [see Plate I, Fig. 1, e.].$^{\circ}$ This minor deformity is symmetrical, however, in each component with reference to the entire organism, being on the inner lateral side of each componental snout and growing from the same region of the roof of each mouth. The characteristic throat warts appear here as two about $18 \mathrm{~mm}$. apart, and equidistant from the median axis of the body. The two outer eyes are also normal, the eyelids being perfectly formed, even to the presence of eyelashes. The median eye is made up of a double eyeball lying within a single socket. The eyelids are fringed with lashes and form an inverted heart-shaped opening, which with its associated parts is perfectly bilateral. The median eye socket is nearly spherical in shape, being $19 \mathrm{~mm}$. in diameter measured transrersely across the head, and $20 \mathrm{~mm}$. in diameter measured in the direetion of the median axis of the monster. Contiguous with the socket posteriorly and separated from it only by a thin septum of bone, is a curious heart-shaped cavity with the apex directed backward. This cavity lies between the two outer eye orbits and was filled with a protrusive mass of pathological brain tissue. Its bony floor and walls are perforated with foramina for the passage of nerves. It measures 23 $\mathrm{mm}$. in diameter across its broadest part, and $25 \mathrm{~mm}$. along its median axis. This is plainly a deformed cranial cavity, and the everted brain thus represents an actual deformation, which must have taken place in an early embryonic stage. It forms an exception, however, to the greater part of the organism, but is at the same time a deformity that is apt to be associated with such monsters; and all cosmobia are secondarily subject to deformities.

sThe terms inner lateral and outer lateral, inner side and outer side are used with reference to the two sides of the components. Median and lateral refer to the whole organism treated as a single symmetrical solid. 
The embryo designated as Teras I represents another progressive stage in the series under consideration. Aside from its value as a link in this series, it has a still greater value in that it records a chapter in the history of early embryonal development of a dicephalon and is, therefore, extremely important in examining the theory that cosmobia are at first perfectly orderly and symmetrical, and that the deviations found in them are due to a lack of balance in later physiological activities. Hence it has seemed best to reserve the study of this specimen for a separate paper, owing to the technical difficulties in studying an embryo of such size. I have noted it in the list of material, however, and describe it here in general in order to make the series as complete as possible.

Teras I was received by Professor Wilder in an excellent state of preservation so that he was able to make from it a set of beautiful serial sections, which have been loaned to me for study. In consequence, Plate II was made from sketches belonging to Professor Wilder, and the description of the creature in toto has been made from his notes.

Teras I corresponds to the specimen of human diprosopus tetrophthalmus represented by Förster [Tafel I, Fig. 4], Hirst and Piersol [page 148, Fig. 74], and Ahlfeld [Tafel IX, Fig. 5]. It measured $22 \mathrm{~mm}$. in length, was bilaterally symmetrical and well developed. The median eye was composed of two eyeballs in one socket; no median ear was present. The two snouts were more separated than in the case of Teras XII, thus defining the embryo as representing a later stage in the cosmobiotic series-a stage between Teras XII and Teras XV.

Concerning the history of Teras XV, I know little, except that it is apparently a fully formed dicephalous lamb delivered at term, and that it lived to be from three to four weeks old. Behind the region of doubling, that is, the head region, the lamb presents externally a perfectly normal appearance. The two heads are identical in contour, and of practically the same size, their differences being extremely slight as the following measurements will show:-Length of a straight line from left ear of head A to extremity of muzzle is $10.5 \mathrm{~cm}$. ; from the right ear of $\mathrm{B}$ to same limit is $10 \mathrm{~cm}$; a similar line from the dorsal rim of the left eye orbit through middle of eye to angle of jaw measures $6 \mathrm{~cm}$. in both heads. An inner lateral line across the muzzle posterior to the nostrils is 3.5 $\mathrm{cm}$. long in $\mathrm{A}$ and $3.8 \mathrm{~cm}$. in $\mathrm{B}$. The distance between the tips of the muzzles is $17.3 \mathrm{~cm}$.

The most noticeable difference between them is in the angle of attachment of the two heads. Certainly one head, at least, suckled 
during the short life of this cosmobion, since the stomach was filled with curds. The appearance of the mouth cavity, together with the fact that the axis of head $B$ makes almost a straight angle with the body axis, indicates strongly that this was probably the suckling head. Head $A$ is turned at a somewhat broader angle from the median axis of the monster, and the snout is directed more ventrally than that of the other component, thus forming a more acute angle between head and chest [see Plate III]. If the mode of suckling in ruminants be recalled, it will be readily seen how very difficult it would be for this head (A) to suckle, since it would necessitate an awkward twisting and distortion of the whole dicephalous region. It seems only logical, therefore, to conclude that the head most nearly normal in position would usurp the feeding function from the beginning and be constantly favored at the expense of position of the other head, so that, although at the present stage the difference in position of the two components is not extremely great, it is quite possible to foresee that if the animal had lived longer, head A would have come to be thrust even further from the normal and to assume an almost parasitic position. ${ }^{6}$ There is still another reason to support my conclusion, which I shall point out when speaking of the blood supply in the head region.

An approximate idea of the stage of doubling of Teras XV may be gained by comparing it with Förster's human diprosopus tetrotus [Tafel I, Fig. 7] and with Hirst and Piersol's [page 149, Fig. 7\%]. The two heads of Teras XV are united in the occipital region, the union involving the bones, thus resulting in a composite occipital. The ears on the inner lateral sides are separate, though the ear of head $B$ is crowded a little above that of the other component. Behind them the heads appear at first sight to be superficially united, but closer examination shows that a union does not really exist, since hair is found growing between and behind the ears down to the composite occipital region. Both outer ears and all four eyes are normal. The brains of this dicephalus have been removed and preserved. These are also normal per se and conjoined only in the region of the medulla oblongata just

'This explains the case told me by Professor Wilder, which he recalls from memory, of an adult double-headed ox widely exhibited about twenty years ago, in which one head, although of practically the same size as the other, did not function in alimentation, but was borne babitually upon the side of the other head, which was held so as to continue the main axis of the body. In this monster the functional head was also the left. 
before it continues backward as a single spinal cord. The larynges and csophagi are separate down to the level of the shoulders (approximately).

The last stage in the cosmobiotic series under discussion that $I$ have to present is represented by a two-headed turtle of the common variety Chrysemmys picta, just hatched, traces of the umbilicus still remaining. Its carapace is a trifle smaller than a twenty-five cent piece. Both carapace and plastron show a beginning tendency toward doubling [see Plate IV, Figs. 1 and 2, $\mathrm{x}$ and $\mathrm{y}$ ]. Components $\mathrm{A}$ and $\mathrm{B}$ are disunited as far back as the shoulder girdles. Two distinct hearts are present. Upon removing the plastron and gently spreading the heads apart, a median papilla is conspicuous between the two necks at the level of the outer fore limbs, and immediately posterior to it in the mid-shoulder region on the ventral side is a tiny median nodule of cartilage with delicate muscles attached. The papilla is unquestionably the anlage of a median pair of fore limbs, and the nodule is probably the beginning of a median donble shoulder girdle. Save for these peculiarities the specimen appears normal in general structure. It represents a stage between the dicephalus dibrachius and dicephalus tribrachius of the liuman species represented by Förster [Tafel I, Figs. 10 and 11]. Ahlfeld portrays a condition more nearly like that of Teras XX [Tafel X, Fig. 10], but Gruber depicts a stage practically identical with it [Tab. III, Fig. 2] - with this exception, that in Gruber's specimen the conical tuberosity is compressed somewhat from the front backward (page 34) while in Teras $X X$ the compression is lateral.

It will suffice for the purposes of the present study to consider but one of the many systems of these organisms. I have selected, therefore, a system that is fundamental to the growth and development of every being, and one that appears very early in embryonal life, namely, the circulatory system. This is functional from its beginning and thus reflects the physiological needs of an organism in every stage of development. Only the arteries in the doubling region and the heart will be considered in the present paper. In each teras described I shall consider the heart and anterior arteries in detail and make comparisons with those in normal specimens of the same species and of approximately the same age. I shall then compare these vessels in the cosmobia themselves, and offer speculative explanations of the variations noted, and endearor to permanently establish the cosmobia in the series already defined. 
The heart and anterior arteries of Teras XII present a striking similarity to those of a normal pig of about the same age. With the exception of a difference in size the hearts are identical. As in the normal pig studied, the heart of XII lies within the mediastinum in ordinary relation to surrounding parts, and extends from about the $3 \mathrm{~d}$ rib to the 7 th. It is a little larger, but the Teras as a whole exceeds the normal animal somewhat in total length; the former, although a little younger, measures $36.5 \mathrm{~cm}$. from tip of either snout along the mid-dorsal line to root of tail, the latter $34 \mathrm{~cm}$. In bulk the bodies are about equal.

The longest lateral dimension of the heart, that is, from apex to dorsal margin of the left auricle, is $43 \mathrm{~mm}$; in the normal specimen it is only $35 \mathrm{~mm}$. The diameter of the organ, measured on its anterior surface across the ventricular border of the auricles, is $30 \mathrm{~mm}$. while the same diameter in the normal pig is but $25 \mathrm{~mm}$. As would be expected, the cavities of the two hearts are in proportion to their external dimensions; otherwise they present no appreciable differences. In both, the foramen ovale and ductus Botalli are still present.

The great vessels that issue from the base of the heart are normal in relationship, and it is not until the origin of the external carotids is reached that any striking differences are observable [Plate V]. The right subclavian together with the right and left common carotids arise from the crest of the systemic aorta by an innominate a centimeter long. The left subclavian arises independently from the convexity of the arch about $2 \mathrm{~mm}$. from the innominate. Near its beginning each subclavian gives off a vertebral artery and the other customary branches for this region. The common carotids pass in normal manner to the componental head, each giving off an inferior thyroid soon after leaving the innominate, and farther headward the superior thyroid. Slightly anterior to the superior thyroid, the common carotid gives rise to the internal carotid and the occipital by a common trunk from its dorsal wall. The continuation of the parent artery now becomes known as the external carotid. It is from this point anteriorly that variations from the normal arrangement of vessels are obvious. Topographically the arteries in this region have responded to the changed structural conditions, but physiologically they maintain a normal value to the tissues supplied by them, a statement which will be proved in a later paragraph.

For a full appreciation of the arterial condition in the dicephalous region a brief comparison of its bony structure with that of a normal 
head is necessary. The double head is broader and flatter, and the snouts are shorter, so that it has a very blunt, almost square appearance in dorsal aspect. Either component measures $10 \mathrm{~cm}$. from tip of snout to the inion; the head of the normal pig studied measures $14.5 \mathrm{~cm}$. This additional length in the normal specimen is due largely to the rotundity in the frontal, parietal, and occipital regions, a quality totally lacking in the dicephalus. The zygomata of Teras XII are spread laterally, which, in addition to the flatness of the roof of the skull, gives the head a much broader aspect through this region, although by actual measurement the distance between the dorsal margins of the outer eyeorbits is less in the Teras than in the normal animal, the former measuring $33 \mathrm{~mm}$, the latter $45 \mathrm{~mm}$. Owing to this narrowness between the orbits and the spreading of the zygomata, the outer eyes of XII have a very dorsal position.

The mandibles on the inner sides of the two snouts are only half as long as the outer ones from symphysis menti to rami. Each of these inner mandibles, instead of articulating with the temporal bone of its respective component, turns its ramus at a sharp angle to the median. axis of the body, and the coronoid and condyloid processes of one mandible interlock with those of the other so that an S-shaped appearance is given to the margins of the bones, and a narrow S-shaped interstice is left between them, for they are not united at this point, but merely overlap. On their inferior borders, however, at the angle of the jaws, they are united by a short symphysis. Lying superficial to, $i$. e., ventral to the symphysis a mass of glandular tissue was removed. From its position it was undoubtedly a median parotid gland. The S-shaped passage just referred to lies posterior to the symphysis. The crowding toward the median line of the monster has forced the interlocked rami to turn outward, that is, anteriorly in the direction of least resistance, thus forming a noticeable median protuberance [Plate I, Fig. 2, f]. The maxillary bones of the inner lateral sides of the two components are spread dorso-laterally, that of $A$ somewhat more than that of $B$. Between them at their posterior margins a small bone has developed which forms a shelf over the protruding rami. Posterior to this region the bones of the roof of the skull are closely knit. The median evesocket and the adjoining brain cavity lie in the median axis of the monster and largely between the outer eye orbits.

I have already called attention to the fact that the common carotid takes the name external carotid immediately after giving off the internal 
carotid and the occipital artery. Normally the external carotid turns abruptly dorso-laterally beneath the digastric muscle, crosses the caudal extremity of the anterior cornu of the hyoid bone between it and the ventral end of the par-occipital process, whence it turns again dorsoanteriorly and divides into its terminal branches, the internal maxillary and the superficial temporal.

Near its origin the external carotid gives off the lingual, which crosses the cranial portion of the anterior cornu of the hyoid and passes to the tip of the tongue imbedded in its tissue and gives off many collateral branches. Close to the lingual arises the facial (external maxillary), which at first lies deep beneath the digastric muscle and submaxillary gland, to which it sends small branches. It sometimes gives origin to the sublingual. The facial then emerges from beneath the gland, courses parallel to the jaw for a short distance, turns abruptly, and mounts the side of the face along the anterior margin of the masseter muscle, whence it divides at an obtuse angle into the inferior and superior labials, which supply the muscles of the lower and upper lips respectively. At the ventral extremity of the par-occipital process the external carotid dispatches a collateral branch, the posterior auricular, to supply the posterior region of the external ear and the muscles of the nape of the neck. Immediately anterior to the posterior auricular, the main artery makes a second turn at the angle of the jaw, laterally and anteriorly and bifurcates into its terminal branches, the larger one in the internal maxillary, the smaller, the superficial temporal. The latter vessel gives off the anterior auricular, and sometimes the masseteric. In my specimen of normal pig, the masseteric arose from the anterior auricular.

A comparison of the above description with Plate $\mathrm{V}$ will show that the same distribution is found in the neck and on the outer sides of the componental head of Teras XII, and that variations from this normal condition are confined to the cramped and altered region between the two inner sides of the components.

If attention is given to component $B$ for a moment, it will be seen that at the point where the left common carotid gives off the left external carotid, the main artery is apparently continued anteriorly and medially by curving slightly across the anterior cornu of the hyoid to a position along the median axis of the body, whence it continues forward and passes between the two componental snouts, winding through the S-shaped passage between the overlapping rami and emerging upon the inner lateral and dorsal sides of the face. Opposite the cranial extremity of 
the anterior cornu it gives off a large branch which distributes itself in the tongue of component $\mathrm{B}$ after the manner of a normal lingual artery, for such it is unquestionably. This lingual sends off a smaller but conspicuous branch to the symphysis menti, which branch enters the mandible through a foramen on its inner lateral side close to the symphysis. These foramina, one on each inner lateral side of the symphysis, are quite large and conspicuous in young pigs. A bristle passed through one of them emerged from the most anterior of the mental foramina. In three specimens examined a definite branch from the lingual passed into each of these foramina, yet I failed to find them named in any of the literature, or given particular mention. Therefore, in order to designate the conspicuous branch that passes into them, I shall refer to them as the sub-symphysial foramina. Both the lingual and the sub-symphysial branch give off many small twigs to the muscles of the tongue. About a centimeter farther forward the main artery gives rise to a pair of lateral branches; one, another lingual with its subsymphysial branch to supply the inner side of the tongue of component $B$, the other suggests the corresponding artery to the inner side of the tongue of component $A$, of which only the sub-symphysial branch has been preserved. The hypothetical former condition is represented in the plate by a dashed line $\left(x^{\prime}\right)$. The parent artery sends off from its dorsal wall many small collateral branches in pairs, which supply the inner lateral borders of the two tongues. Immediately anterior to these a single branch is given off, which proceeds dorsally in the median plane and passes into the interior of the head just posterior to the angle of the united mandibles. This could not be followed beyond this point without spoiling the specimen for further investigation. In the Plate it is deflected to one side in order to render it visible. The distribution of the branches of the main artery thus far establishes it as a MEDIAN Compound ExTERnal CARotid, fulfilling a normal function for component $\mathrm{B}$ and in addition partially supplying component $\mathrm{A}$. The only striking deviation from the normal distribution in component $B$ is that both linguals arise from the same external carotid, instead of one lingual from each. The remainder of the ventral surface of component $A$ is supplied by collateral vessels from the right common and external carotids as would be expected normally. Note, however, that there is a reduction in the tongue supply. It is nourished by only one lingual artery, which has a normal origin but does not give off a sub-symphysial branch. It will thus be seen that the tongue of component $\mathrm{A}$ depends 
solely upon its outer lingual artery for nourishment. After giving off. the single dorsal branch which strikes into the interior of the head, the median compound external carotid continues forward through the Sshaped interstice and emerges upon the face as already described. At the first curve of the $\mathrm{S}$ it gives off two lateral branches, one turning to the right to course over the inner lateral and dorsal surfaces of the face of component $\mathrm{A}$, the other turning to the left to a like distribution over component $\mathrm{B}$.

The subsequent course of their lesser branches is strikingly identical. Each gives off near its origin a delicate branch which may be a pharyngeal (?), and just beyond a very short artery which almost immediately bifurcates into two terminal branches that break up in the muscles at the angle of the mouth. These branches are obviously superior and inferior labials, therefore their stem is a very much shortened facial, which is quite in keeping with the anatomical condition, for the shortness of the inner mandibles brings the ramus and the angle of the jaw in a perpendicular line to the angle of the mouth. Immediately beyond the facial a long slender artery passes dorsally and caudally over the roof of the cranium and loses itself in the tissues around the outer periphery of the median eye. These terminal twigs had not taken the injection mass, and it was difficult to trace them thus far, but there is no question in my mind but that the artery which gives them origin is a superficial temporal. Near its beginning this vessel gives off an insignificant branch which ramifies the tissues at random over the median dorsal region anterior to the median eye. This may be an anterior auricular which has no legitimate distribution, owing to the fact that there is no median ear to call it into normal physiological service. Beyond the root of the superficial temporal an attenuated branch from the external carotid mounts to the dorsal surface of the snout and unites with one of the two branches which ramify this region and terminate in a single stem issuing from a foramen. The position of this foramen together with the fact that from it also issue a few nerve fibers establish it as a greatly reduced infraorbital foramen. A similar foramen, exhibiting identical relationships, is also present upon the inner side of the other component. Obviously, then, the blood-vessel is an infraorbital artery with its terminal branches, and the attenuated communicating branch is merely an anastomosing branch from the facial.

Having given off the two lateral branches, whose lesser branches have just been followed over the face, the main artery continues its serpentine 
path between the overlapping rami and emerges at its most dorsal part, only to turn abruptly at a sharp angle and disappear into the interior of the cranium between the projecting rami and the protruding shelf of bone above them. Again the value of the specimen for future study opposed further investigation and I did not open the cranium to follow the course of this artery. Yet I think no serious check has been placed upon its identification, for from the data at hand I feel that it may be safely interpreted as a Mediax Compound Interanar Maxiluary. Although the median eyeball had been removed with no special reference to the preservation of underlying parts, there are still present within the orbit traces of nerve fibers and other tissue. On the anterior surface of the orbit, on either side of the median axis, and close to the roof of the cranium are two minute foramina. Issuing from them are two black threads, so to speak, which I mistook at first for discolored nerve fibers, but which upon closer examination proved to be injected blood vessels. It takes but a slight stretch of the imagination to suppose them branches of an internal maxillary, which normally divides within the eye-orbit, and such a vessel is the one in question. If this be granted, it is not diffcult to trace back to their parent artery the intercranial course of the infraorbitals, whose external ramifications have already been followed, and whose origin is known to be from an internal maxillary. These two suppositions seem to me to render valid the identification of the artery under discussion as a Median Compound Internal Maxillary. The hypothetical relations are indicated in the plate by dotted lines.

It remains to be demonstrated how the changes in the mid-region have come about, and their significance. In this cosmobiotic series of organisms leading through dicephali and ischiopagy to duplicate twins, Teras XII represents one of the earliest stages. This specimen is developed but a little beyond normal and the doubling ceases externally at about the level of the angle of the mouths. Naturally the blood vessels of this region, as well as the other parts, exhibit the doubling also. As a cosmobiotic head passes beyond a single individual in development it grows further and further away from that single stage, but nearer and nearer to two separate and distinct heads. It should be borne in mind that I do not mean that these progressive changes take place in a single individual. Each represents but one stage in the series, individual links in a chain, which may be made up of an infinite number of links of which the last two represent duplicate twins.

Since the arterial system supplies all parts of an organism, it forms by its distribution an outline of the entire anatomy of the individual, 
and since the present study is designed especially to delineate a series of consecutive stages of a given cosmobiotic series, the arterial system will illustrate the theory emphasized in this paper that such a series may be conceived as a gradual separation of component halves beginning with normal individuals and ending with duplicate twins. Of such a series, which my specimens represent, the monster in question, Teras XII, comes first and represents an initial stage in the splitting of the organism, a process which here involves only the anterior part of the head. Therefore there is present in this creature the forepart of two separate heads, that is, two snouts and both sides of two faces, but owing to the lack of division of the remainder of the head the inner sides of the two faces are close together and all intervening tissues are greatly cramped. Nevertheless, such division as is present is responsible for the physiological necessity of a double blood supply to the divided region, and nature has responded to the call as best it could. The division has not yet extended far enough posteriorly to demand two separate external carotids to the inner sides of the two components, but one median vessel has heen able to meet the emergency by giving off double the normal number of branches, one moiety of which supplies component $A$, the other component B. Thus the median external carotid is made up of elements of the inner external carotid of $A$ and also of $B$ (A's left and $B$ 's right), and for this reason I have called the main median artery "compound."

Normally a common carotid, external carotid, and internal maxillary form a single compound curve. If such vessels should develop in a space too crowded to permit them to assume their natural curve, they would become elongated into a straight tube. This is the condition in the median region of Teras XII; the median compound external carotid and internal maxillary have been forced to develop as a straight tube owing to the cramped condition in this region.

An examination of Plate $V$ will demonstrate that in the neck region and on the outer sides of the componental head the amount of space and other conditions are normal, and here the arteries are distributed in normal manner. This is also true in the median region wherever the topographical changes leave room for normal behavior, as for example, the distribution of the branches of the median compound external carotid which supply the inner lateral and dorsal sides of the two components. Only a single hypothetical branch, or capillary connection between the median compound external carotid and the outer external carotid of 
component $A$ is necessary to complete the symmetrical condition that I believe existed at an earlier period in the development of this Teras. This branch is indicated in the plate by a dotted line [Plate $\mathrm{V}, \mathrm{x}$ ]. Some secondary variations are present, for example, the origin of both linguals of component B from one external carotid, instead of one lingual from each, and the loss of one lingual artery by component A, but these . are of minor importance and are the results of continual solutions of physiological problems during the entire development of the organism.

While it cannot be denied that this creature is "unusual," it is obvious, nevertheless, that it is perfectly symmetrical, that with the exception of the everted brain it is in no sense pathological, but that on the contrary it has developed according to the laws of an orderly living being, and therefore has a right to the title "Cosmobion," and a definite place in the cosmobiotic series with which this investigation is concerned.

As the doubling in the dicephalus group increases, so also the divergence of the two components increases. This is well illustrated by the two-headed lamb (Teras XV), which represents the next stage in the series. In this specimen the heads are separate as far back as the occipital region. Each head has its normal parts and organs, e. g., two eyes, two ears normally placed and normally developed. Obviously, then, the doubling has progressed more posteriorly than in Teras XII. The following description and comparison will show that the blood vessels have perfectly reflected these other anatomical changes.

The heart of the dicephalous lamb is single, and fully three times the size of that of the cosmobiotic pig, but is proportionate to the size of the lamb. Its size may be easily approximated by the following measurements taken along the same axes as in the double pig:- the longest lateral line measures $6 \mathrm{~cm}$., its transverse diameter across the anterior surface is $5 \mathrm{~cm}^{7}$ In shape the heart of Teras $\mathrm{XV}$ is identical with that of a normal lamb, and may be said to be shaped like an inverted pear, but it differs from that of a pig, the heart of which is roughly acornshaped. It is more elongated and pointed than a pig's heart, its posterior face is slightly more concave, its right face is less bulging, and it has not the appearance of having two apices that is so conspicuous in a pig's heart. In both, the auricular appendages are rather flat. The heart of the double lamb extends from the first rib to the fifth, which by com-

'It should be mentioned here that in all the terata the measurements of the heart, and its position in the thoracic cavity, were taken with the specimen in a dorso-cumbent position and after long preservation in alcohol. 
parison with that of Teras XII is more anterior in position. A perpendicular lateral line from apex to middle of the base of the organ passes through the second intercostal space. Thus it is seen that its longitudinal axis is nearly at right angles to the median axis of the body, while that of the double pig is directed antero-posteriorly. The apex of the heart lies a little to the left of the mid-line of the body against the sternal wall, which at this point presents externally a slight bulging.

The exterior of the heart appears in general quite normal, but its interior and the great vessels arising therefrom present some interesting variations, traceable to early embryonal conditions as will be shown later. The right ventricle is small in proportion to the size of the heart, occupying about a third of the ventricular mass. The left ventricle is correspondingly larger, occupying the remainder of the ventricular portion. It is a curious fact that the ventricles (and the auricles) of Teras XV have seemingly changed position with those of a normal heart, for in the Teras the right ventricle has the position and extent of a normal left ventricle, and vice versa for the left ventricle (and auricle). The right ventricle has a very thick wall, equal to that of the left ventricle. Possibly the greater extent, and therefore the greater capacity, of the right ventricle and the greater thickness of its walls are compensations for its lack of size. It has an extremely posterior position, so much so that in a median longitudinal section it is not visible at all, but shows only in cross section. The altered position of the ventricles suggests an unusual twisting during the early development of the organ, but the heart gives no other evidence of such a proceeding. The right auricle is proportionally smaller than the left, and each opens into its respective ventricle in normal manner. A partially obliterated foramen ovale is still present. So far as position and extent are concerned, it would be very easy to mistake the right ventricle for a normal left and the left for a normal right, but the auricles and the great blood vessels that communicate with them respectively leave no room for error in identification. In the following description I shall use Chauveau's nomenclature, since the origin of the arteries from the heart differs somewhat in lamb from that in pig, and a slightly different nomenclature is used. The differences are those characteristic of ruminant and non-ruminant animals.

In a normal lamb the first part of the systemic aorta is termed the aortic trunk. This arises from the basal portion of the left ventricle and very soon divides into an anterior and posterior aorta. The anterior aorta is short and terminates in the right and left brachial (sub-clavian) arteries. The right subclavian, near its divergence from the left, gives 
off anteriorly a short trunk, the cephalic, which in turn divides into the right and left common carotids. The main difference to be noted in this condition and that found in normal pig (also in Teras XII) is that in the latter no anterior aorta exists, since the sub-clavians arise independently from the aortic arch. The common carotids pass to the head in normal manner, giving off en route the customary branches.

The systemic aorta of Teras XV arises as an aortic trunk from the basal portion of the left ventricle, and from the first is directed slightly dorsally and posteriorly, thus beginning immediately at its origin to arch gently backward. It curves over the root of the left lung and crosses the trachea and oesophagus diagonally to the right. About opposite the third rib the arch is completed, the aorta resumes a median position and continues backward as the posterior aorta, lying along the mid-ventral surface of the vertebral column deep within the dorsal mediastinum and giving off in its course the usual intercostals. The aortic trunk is conspicuously large (diameter $15 \mathrm{~mm}$.), but tapers gradually as it is continued backward into the posterior aorta whose uniform diameter is $11 \mathrm{~mm}$.

The pulmonary artery arises from the basal end of the right ventricle, but owing to the position of the latter, the origin of the pulmonary trunk is immediately posterior to that of the systemic aorta, and not anterior to it as it would be normally. Therefore the convexity of the heart between the anterior margins of the auricular appendages is pronounced in Teras $\mathrm{XV}$ by the systemic aorta, and not by the pulmonary artery. Also as a result of the position of the right ventricle, the pulmonary artery of Teras XV courses parallel to the aorta on its posterior side instead of accompanying it on its right side, and is covered in part by the right auricular appendage, normally by the left. About a centimeter and a half from its margin the pulmonary artery bifurcates into a right and left branch, each of which redivides into smaller branches at the root of the Iung and enters it together with the bronchi. Near the crotch of the bifurcation each pulmonary branch gives off twigs to the bronchus. The trunk of the pulmonary still retains a well defined ductus Botalli, six millimeters in diameter, which unites with the posterior aorta a few millimeters posterior to the anterior aorta. Between the two the aortic arch presents a left lateral constriction, analogous to the "aortic isthmus" in human beings. ${ }^{8}$ The aortic trunk is short and at its posterior ex-

\footnotetext{
${ }^{8}$ Quain, Elements of Anatomy, Vol. II, Part II, Angeiology, p. 384. The diameter of the aorta at the isthmus in Teras $X V$ is $91 / 2 \mathrm{~mm}$, and immediately anterior and posterior to it $12 \mathrm{~mm}$.
} 
tremity divides into the anterior and posterior aorte. The anterior aorta is likewise short and terminates in the left subclavian and a cephalic, which in turn bifurcates into right and left common carotids to supply HEAD B. The right subclavian, instead of arising from the anterior aorta at the origin of the left, has retained a dorsal origin, and arises from the dorso-lateral (right) wall of the posterior aorta at the extremity of the aortic arch. It crosses the dorsal surface of the trachea and osophagus diagonally and to the right and arrives at a position opposite the origin of the left subclavian. It then arches over the first rib on the right side of the body and continues its course to the right forelimb in normal manner.

Head $\mathrm{A}$ is not supplied by any portion of the arterial system thus far described, but has an independent supply direct from the heart. Parallel to and close beside the aortic trunk there arises from the left ventricle another artery of lesser diameter ( $8 \mathrm{~mm}$.), which is continued anteriorly and to the right of the trachea to a point a little posterior to the origin of the common carotids destined to supply head B. Here this new vessel also bifurcates into right and left common carotids to supply HEAD A. Upon making a longitudinal section of the heart a few millimeters to the normal right of the median axis, a small cavity was opened up which is in communication with the left ventricle by means of a semilunar valve. During normal derelopment the semi-lunar valve marks the division between ventricle and aortic bulb, and thus the new cavity is shown to be a new bulbus arteriosus. Therefore the vessel arising from it is a second aorta, and since it is continuous with the cephalic trunk, it may be termed an aorto-cephalic trunk. It gives off no branches, since all that are needed are given off by the systemic aorta which supplies component $\mathrm{B}$, but terminates in a right and left common carotid destined to supply head $A$. Just above the semi-lunar valve but posterior to the root of the aorta-cephalic trunk, there arises from the bulbus a small, short artery which crosses over to the other aortic trunk on the posterior side, and unites with it about $7 \mathrm{~mm}$. from its root. This branch is probably the remnant of a primitive arterial arch, as will be shown presently.

The independent arterial supply to head $\mathrm{A}$ is of great importance to the cosmobiotic theory. After following the course of the arteries in the two heads, I shall offer hypothetical explanations of the conditions found in the roots of the great blood vessels, and point out their significance.

Since there are present in Teras XV two completely separated heads, each with its normal parts, the heart is called upon to furnish a double 
blood supply, not by compromise as in Teras XII where a median compound ressel was sufficient to meet the emergency, but by providing two separate and distinct head supplies. Therefore, the course of the arteries from the origin of the four common carotids is almost identical in the two heads, and furthermore, the distribution is in general as normal as it would be in two separate lambs standing side by side [see Plate VI]. The distribution of the head arteries is also very similar to the condition in normal pig, the chief differences being changes characteristic of ruminant and non-ruminant arteries. It does not seem necessary, therefore, to describe in detail the course of these arteries, but only to call attention to salient differences. The first chief difference between pig and lamb, normal and cosmobiotic, is that in pig there is no anterior aorta. The subclavians arise independently from the aortic arch; the right subclavian gives rise to the common carotids by a short innominate trunk, which is practically the same as the cephalic trunk of the lamb, only shorter. Chauveau ${ }^{9}$ claims the absence of an internal carotid artery in sheep, which is compensated by a branch from the occipital. Since the internal carotid frequently arises by a common trunk with the occipital, I am inclined to think that Chauveau's occipital branch and the internal carotid are one and the same vessel.

The difference in origin of the linguals and facials can scarcely be called a characteristic difference, for they arise by a common trunk from the external carotid quite as frequently as by separate origins. Aside from the rise of the great arteries from the heart, the differences between corresponding arteries of pig and lamb that have been pointed out, and others that have not, are of minor importance, since they apply only to origin and not to distribution, and occur quite as frequently in normal organisms as in monsters. ${ }^{10}$ Between heads A and B of Teras XV only two differences are worthy of attention. The most striking is the absence of one lingual in head $\mathbf{A}$; the one present courses along the middle of the tongue instead of to one side. This single artery to the tongue of head $\mathbf{A}$ is the point I had in mind when I stated earlier in the paper that there was a third reason for supposing that head A had not suckled during the life of the cosmobion. If this tongue had functioned very

"Chauvean, The Comparative Anat. of Domesticated Animals, p. 592.

${ }^{10} \mathrm{Chaureau}$. Ibid., p. 520. "In a purely anatomical and physiological point of view (however) these anomalies are of no moment, as it matters little whether the blood comes from one source rather than another . . . provided its relations are not altered, and the principle of immutability of connections is maintained." 
much it would have needed a normal blood supply to maintain it in a healthy, vigorous condition. The second difference referred to is the apparent absence of an independent occipital of its own to supply the dorsal neck region on the inner side of head A. It is apparently supplied by an occipital arising by a common trunk with the one supplying the inner side of head B. Both aie greatly attenuated and insignificant.

The subclavians of the double lamb give off their normal branches, but since the right subclavian arises from the dorsal aorta, it does not give origin to its branches near its beginning as does the left, but from that portion of it which brings the branches in normal relation to the parts supplied by them [Plate VI].

How are the arterial conditions in Teras XV to be explained? The conditions in the head region have already been explained, so that all that remains to be accounted for here are the arteries that lie in the transverse zone between the heart and the region of the complete doubling. This consists mainly of an extra aortic trunk, the aorto-cephalic. It is readily seen that if in accordance with the theory set forth in this paper, the doubling of Teras XV had extcnded much farther posteriorly the heart as well as the anterior arteries would have been involved and thus there would have been ultimately two separate hearts, probably contained in two separate pericardial chambers. It is possible, however, to conceive of a degree of doubling which involves part, but not all of the heart, and it seems probable that this is the case in Teras XV. But in order to understand such a condition and interpret it correctly one must imagine this condition, not as in an adult heart, but as in the embryo.

Since the early formation of the heart is the same in all vertebrates, and since the arteries in all develop from six primitive arterial arches, it is possible to suggest the changes that have taken place in all the terata by diagrams representing the varying degrees of doubling and the changes that have taken place in the primitive arches, for all are capable of explanation by referring back to the normal vertebrate condition. The usual diagrammatic representation of the normal transformation of the six primitive arches is classic, and to compare with this I have reduced the actual condition in the terata studied to similar diagrams representing the way in which the primitive arches probably existed in these creatures. For the sake of easy comparison I insert here a text figure illustrating the normal mammalian changes in the primitive arterial arches (Text figure 1). The solid black lines in all the diagrams represent the permanent condition in the specimen, the dotted lines the 
arches or parts of arches sacrificed. As text figure 1 represents the underlying condition in normal mammals, so also text figures 2 and 3 represent the underlying condition in Teras XII and XV respectively, for as soon as the arches began to appear in the Terata they were in the form represented in the diagrams. In other words, they did not make their appearance as in a normal mammal and later acquire duplication, but on the contrary, the doubling of the arches was present from their beginning.

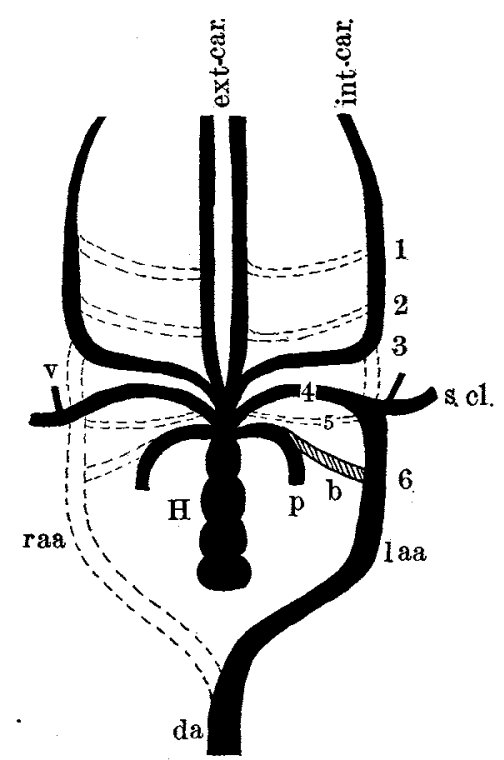

Text FIg. 1. Diagram showing the transformations in the primitive arterial arches in normal mammals.

$1,2,3,4,5,6$, The six primitive arterial arches; ext. car., External carotids; int. car., Internal carotids; H., heart; p., Pulmonary artery; b., Ductus Botalli; s. cl., Subclavian; V., Vertebral artery; raa., Right aortic arch; laa., Left aortic arch; da., Dorsal aorta; mcec., Median compound external carotid (Teras XII); ab., Aortic bulb divided (Teras XV); x., communicating branch between components A and B (Teras XX).

At the stage which the diagrams represent the heart is still a median straight tube, its most posterior portion being the sinus venosus, the next anteriorly the common atrium which communicates freely with the common ventricle, and most anteriorly the aortic bulb which is continued into the aortic trunk. The aortic trunk bifurcates, each moiety arching backward to the median axis of the body posterior to the heart, 
whence it very soon unites with its fellow to form a single tube, the dorsal aorta. Anterior to the bifurcations of the truncus arteriosus three arterial arches have developed in turn, and posteriorly two, making in all the six primitive arterial arches. Brieffy the normal changes that take place in these arches in mammals are:-

(a) The first and second arches disappear.

(b) The dorsal trunk between the third and fourth arches disappears.

(c) The third arch together with the anterior portion of the dorsal aorta thus cut off forms the internal carotid.

The ventral trunk anterior to the origin of the third arch forms the external carotid, and the intervening ventral portion between the third and fourth arches becomes the common carotid.

(d) The left moiety of the fourth arch together with the posterior portion of the left dorsal aorta becomes the permanent mammalian aortic arch.

(e) The fifth arch, which from the beginning is rudimentary, disappears.

(f) A portion of the sixth arch becomes the pulmonary artery. On the right, the remainder of the arch disappears, but the corresponding portion on the left side remains in connection with the permanent aortic arch during foetal life as the ductus Botalli.

(g) When the aortic bulb divides longitudinally, the sixth arch comes to communicate with the right ventricle, and the remaining vessels with the left ventricle.

In the diagram representing the condition in Teras XII at this early embryological period (text figure 2), it will be seen that the heart and arches six, five and four are normal, and that as the divergence anteriorly begins to be felt, the anterior arches show corresponding changes, and in proportion as the amount of duplication is slight, so also the modifications of the arterial arches are slight, the only difference from normal being an increase in the ventral trunk of the third arch, which anteriorly gives rise to the median compound external carotid.

In the double lamb (Teras XV) it is obvious that there has been from the beginning a greater degree of doubling of these elementary blood vessels. There is present the beginning of two hearts and two sets of arterial arches (Text figure 3). Already the aortic bulb has divided, and the semi-lunar valve has developed between the ventricle and the new bulbus arteriosus. Posterior to the bulbus the heart shows no duplicating tendencies. The communicating branch which passes from one aortic 
trunk to the other is probably a portion of the fifth arch that has persisted, for its origin from component $\mathrm{A}$ is above the semi-lunar valve and its insertion into component $\mathrm{B}$ is below the normal aortic arch. It has no connection with the pulmonary system, and therefore cannot be a portion of the sixth arch. The dorsal origin of the right subclavian is an anomaly of common occurrence (Quain), but the present case differs from the usual condition under such circumstances in that the dorsal portion utilized in forming the subclavian also gives rise to the right

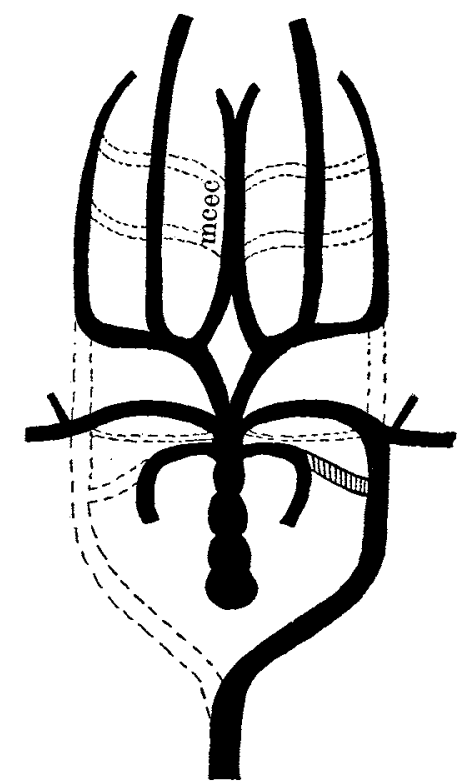

Text Fig. 2. Diagram showing the transformations in the primitive arterial arches in Teras XII.

vertebral, whereas usually, under a like condition, the anterior portion of the right fourth arch becomes the vertebral. The first, second and third arches are obviously normal, but in duplicate. Such an embryonal vascular condition, although suppositional, would fix the future development of the organism of which it is a part, and, it seems to me, would terminate in such an adult condition as exists permanently in Teras XV.

The next and final cosmobion in the series that $I$ have to present will demonstrate the hypothesis that as the doubling extends farther and farther posteriorly, the heart becomes more and more involved. This 
stage is represented by a two-headed turtle, Teras XX. Its gross anatomy has already been described and needs no repetition. The blood vessels in this organism were followed with some difficulty, owing to the smallness of the specimen and the fact that the blood ressels were not injected, and the animal had been preserved by being thrown alive into alcohol of

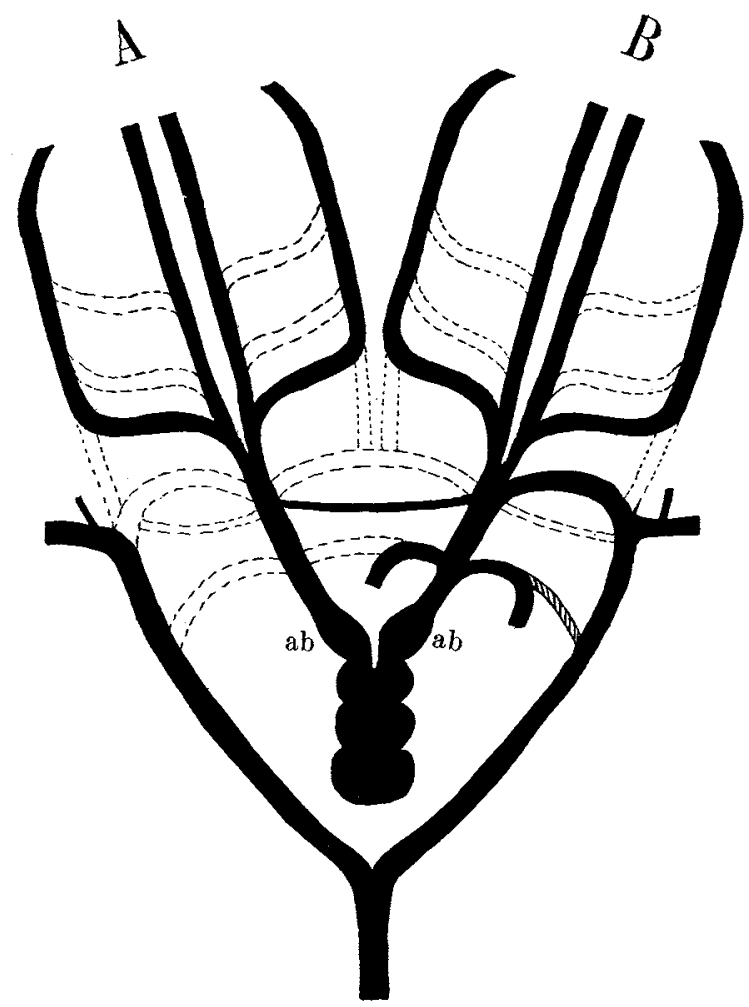

Text FIg. 3. Diagram showing the transformations in the primitive arterial arches in Teras XV.

unknown strength before it came into the hands of scientific persons. Although phylogenetically Teras $\mathrm{XX}$ is more primitive than the other specimens studied, its position in the cosmobiotic series is not altered, for cosmobia are not limited to any one genus and species, the qualities involved being applicable to all vertebrates.

The duplicating tendency has progressed so far in this specimen that not only the heads, but also the necks are entirely separate and distinct 
as far posteriorly as the shoulder girdles, where, it will be remembered, the anlage of a median pair of fore-limbs and a median double shoulder girdle are present [Plate IV, Fig. 3, $a$ and b].

If the cosmobiotic theory is tenable, the heart of Teras XX may be expected to show a greater degree of doubling than does the heart of the preceding Teras. An examination of Plate VII will support this hypothesis, for it is at once obvious that there are present two separate hearts, each supplying a complete normal set of arteries to each component and connected one with the other only by a very short communicating branch between the inner subclavians which pass to the anlage of the median pair of fore-limbs. For the sake of clearness the arteries have been separated somewhat more in the illustration than they are in the specimen, and the sinus venosi and branches of the dorsal aorta have been omitted.

A description of a normal chelonian heart will suffice for the hearts of Teras XX, and for the sake of easy comparison I repeat here very briefly the conditions found. The heart of a turtle has but three chambers, one ventricle and two auricles. The ventricle is not divided by a septum into two complete cavities as in the mammals studied, but only partially so, hence there is a vital difference in the character of the blood passing to and from the heart. But it is outside of the limits of the present investigation to go into details of reptilian versus mammalian circulation, since the difference would have no direct bearing upon the cosmobiotic series. Owing to the smallness of Teras XX, it would have been impossible to study the interior of the hearts without making serial sections, and that seemed hardly necessary, for all the other circulatory conditions being normal, it seems wholly probable that the interior of the hearts is also normal. The right auricle receives venous blood from the body, the left the oxygenated blood from the lungs through the pulmonary veins. The single ventricle lies posterior to the auricles and is partially divided into a right and left portion, the right one being known as the cavum pulmonale. The left portion is the larger of the two and is subdivided into a cavum arteriosum on the left, and a cavum venosum on the right.

The pulmonary artery of each component arises as in normal from the carum pulmonale and almost at its beginning bifurcates into right and left branches, which supply the right and left lung respectively. The right branch passes dorsally to the other ressels arising from the right hand portion of the ventricle and courses parallel to the right aorta for some 
distance, it then crosses ventrally to the right aorta and enters the lung. The left pulmonary branch passes more directly to its lung, but courses parallel to the left aorta for a portion of the way. The artery arising apparently next to the pulmonary is the left aorta and the third vessel to take origin from the ventricle is the right aorta; each crosses the other close to the heart. Thus it is seen that in turtles (and all other reptiles) two aortic arches are present, in mammals only one.

The right aorta arches over the right pulmonary artery and bronchus, and receives a communicating branch from the left aorta about opposite the fourth dorsal vertebra. The left aorta passes round the left bronchus and pulmonary artery to a dorsal position and ends by dividing into three main trunks, a gastric artery, superior mesenteric, and a gastroduodenal artery. A portion of the gastric artery continues as the communicating branch to the right aorta. In the plate these branches have been omitted in order to render the illustration more simple.

The right aorta is covered close to the heart by an innominate artery, which it gives off. The innominate divides almost immediately into the right and left subclavians, and the right and left common carotid arteries. The subclavians are at first ventral to the carotids, but soon diverge. Each gives off a minute thyroid, an ascending cervical, a vertebral, axillary and brachial arteries. The remainder of the subclavian continues posteriorly along the edge of the carapace in the hollow of the marginal plate as the internal mammary, and anastomoses with the epigastric. It was impossible to follow all of these subclavian branches in Teras XX, but otherwise Plate VII demonstrates a perfectly normal arterial distribution to each component, the only connection between the duplicated parts being through a short communicating branch between the inner subclavians (Plate VII, $x$ ).

If the vascular condition in the double lamb be recalled and a comparison be made between it and the two-headed turtle, it is at once obvious that in the latter the division of the component parts of the heart and anterior arteries has progressed farther. In the lamb only the bulbus arteriosus had divided, but in the turtle the division has extended through the common ventricle, auricle and sinus, thus dividing the heart into two identical halves, or in other words, forming two distinct hearts, each destined to give a normal arterial supply to an anterior moiety of the monster, and retaining only a slight communication with each other through a small branch from the inner subclavians. 
Since Teras XX presents a normal, but double arterial supply, it is not difficult to represent diagrammatically the transformations of the primitive heart and arterial arches. Text figure 4, illustrating the normal changes in a chelonian, is inserted for ready comparison. It differs from the normal mammalian changes in two respects, first, both the right and left fourth arches persist, second, the ductus Botalli functions permanently throughout the life of a chelonian. A comparison of this diagram with text figure 5 , which represents the underlying condition in Teras XX, will show at once that in the latter each moiety is identical

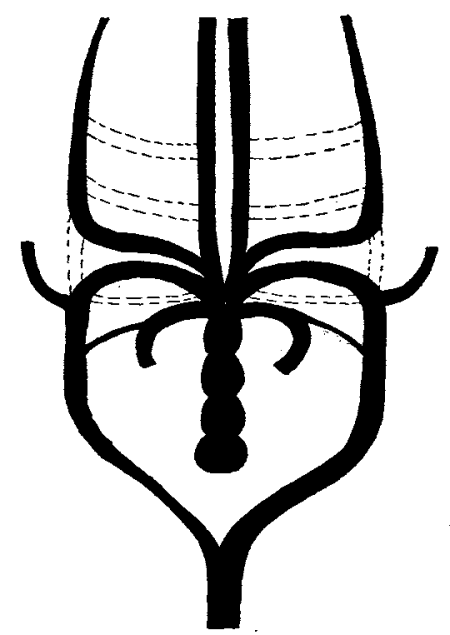

TEXT FIG. 4. Diagram showing the transformation in the primitive arterial arches in a normal reptile.

with that represented in the former, and that the communicating branch between them may suggest a slight increase in the fourth arch in the median region. Although in the diagram the hearts are rather widely separated, it should be mentioned that in the specimen they are quite close together, the sinus venosi being adjacent, and the heart of component $B$ has a slightly more anterior position than that of its fellow; a line drawn across the ventral border of the auricles of the heart of $\mathrm{A}$ would be on a level with the most posterior portion of the ventricle of heart of $B$. 


\section{Summary.}

Four cosmobia have been studied and general comparisons made. Of three of them the heart and anterior arteries have been made the subject of special investigation. The study has demonstrated:-

(1) That primarily each Teras has developed in an orderly, symmetrical manner in accordance with the laws of growth inherent within it.

(2) That as the structural parts of the components diverge, the arteries in the region involved reflect the deviation part for part, and the more posteriorly the divergence passes the more the heart becomes involved.

(3) That the divergence of all the parts involved is perfectly uniform and symmetrical.

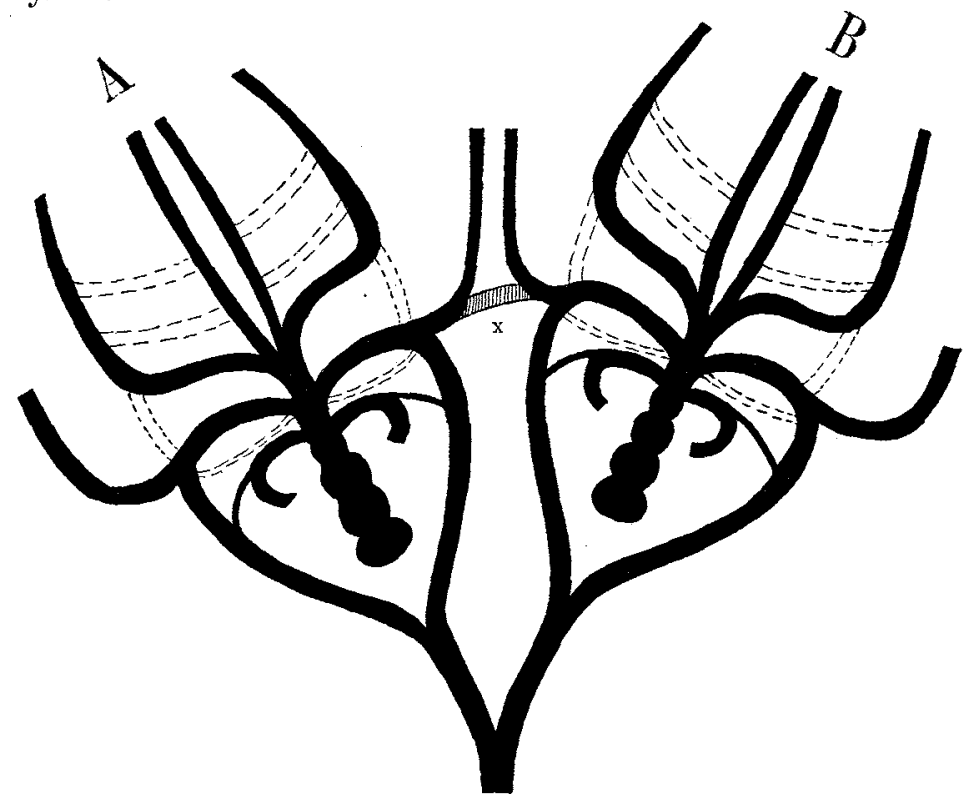

TeXT Fig. 5. Diagram showing the transformations in the primitive arterial arches in Teras XX.

(4) That in each case it has been possible to refer the vascular arrangement back to an embryonic condition known in normal organisms by considering this latter condition as modified through various degrees of doubling. This has been done by reducing the teratological conditions to diagrams.

(5) That it should be emphasized that in explaining these cases they must be considered double to a definite extent from their beginning, 
and that the embryonic arterial conditions in the Terata did not pass from single to double during individual development, but unfolded themselves from the first in accordance with the diagrams given to explain each case.

(6) That starting from such a condition, each case was modified by its physiological necessities.

(7) That it is possible, therefore, to conceive of these terata as representing progressive stages in a single series of "orderly living beings;" which begins with organisms less than a single individual and approaches duplicate twins as the other limit, and includes between these limits normal beings and creatures of more than one but less than two complete individuals.

(8) That such a cosmobiotic series is not confined to any one genus or species, but is applicable to all vertebrates.

In conclusion, I take pleasure in expressing my thanks to Dr. H. H. Wilder, whose interest in the present research has been unceasing, and whose practical suggestions and many kindnesses have been invaluable.

Smith College, Northampton, Mass., May 20, 1908.

\section{BIBLIOGRAPHY.}

Ahlfedd, F. Atlas zu die Missbildungen des Menschen, I Lieferung, Tafel I-XXIII, Leipzig, 1880.

Balfour, F. M. A Treatise on Comparative Embryology, Vol. II, 1881.

Bojanus, L. H. Anatome Testudinis Europær, 1819-1821. Reprinted in Berlin, 1902.

Broomelt, I. N. Anatomy and Histology of the Mouth and Teeth, Philadelphia, 1899.

Chauveau, A. The Comparative Anatomy of the Domesticated Animals. Translated by George Fleming, New Yorls, 1884.

Davidson, A. Mammalian Anatomy with special reference to the Cat, Philadelphia, 1903.

Duval, Mathias. Atlas D'Embryologie, Paris, 1889.

Ellenberger, W., and Baum, H. Anatomie des Hundes, Berlin, 1891.

Frower, Wilitam H. Osteology of the Mammalia, London, 1885.

Förster, Dr. A. Die Missbildungen des Menschen, Jena, 1861.

Gegengatr, Carc. Elements of Comparative Anatomy, Leipzig, 1898.

Gerrish, F. H. A Text-Book of Anatomy, Pbiladelphia and New York, 1902.

Gray, H. Anatomy, Descriptive and Surgical, Philadelphia, 1901. 
GreIL, ALFred. Beiträge zur vergleichenden Anatomie u. Entwickelungsgeschichte des Herzens u. des Truncus Arteriosus der Wirbeltiere, Morph. Jabr., Bd. XXXI, S. 123-310, 1903.

Gruber, Wenzel. Missbildungen, Mémoires de L'Academie Impériale des Sciences de St. Pêtersbourg, VIIe Série, Tome II, No. 2, St. Petersburg, 1859.

Mertwig-Mark. Text-Book of the Embryology of Man and Mammals. London, 1892.

Irrest and Piersol. Human Monstrosities, Part III, Philadelphia, 1892.

His, Willlak. Anatomie menschlicher Embryonen, Text and Atlas, Leipzig, 1888.

Howell, W. H. Dissection of the Dog, New York, 1889.

HuXley, Thomas H. A Manual of the Anatomy of Vertebrated Animals, New York, 1883.

Johnson, R. H. Axial Bifureation in Snakes, Trans. Wisconsin Acad., Vol. XIII, 1901.

Johnston, J. B. The Nervous System of Vertebrates, Philadelphia, 1906.

JoRDAN, D. S. A Manual of the Vertebrate Animals of the Northern United States, Chicago, 1899.

KAESTNER, S. Doppelbildungen an Vogelkeimscheiben, Arch. für Anatomie ،. Physiologie, Anat. Abt., 1907.

Kollmann, Juluus. Handatlas der Entwickelungsgeschichte des Menschen, Band I u. II, Jena, 1907.

KöLLTKER, A. Entwickelungsgeschichte d. Menschen u. der höheren Thiere, Leipzig, 1873.

MIcMurrich, J. Playfair. The Derelopment of the Human Body, Philadelphia, 1906.

MaLI, F. P. A Study of the Causes Underlying the Origin of Human Ionsters, Jour. of Morphology, Vol. XIX, No. 1, 1908.

Marshall, A. M. Vertebrate Embryology, New York, 1893.

Martin, H. N., and Moale, W. A. A. Handbook of Vertebrate Dissection. Part I, How to dissect a Chelonian, New York, 1895.

MeckeL, J. F. De duplicitate Monstrosa, Berlin, 1815.

Mrror, Charles S. Laboratory Text-Book of Embryology, Philadelphia, 1903.

Mrvart, St. George. The Cat, New York, 1881.

Owen, Sir Richard. On the Anatomy of Vertebrates. Vol. I, Fisbes and Reptiles, London, 1866. Vol. II, Mammals, London, 1868.

PARKER, W. K. On the Structure and Development of the SkuIl in the Pig (Sus scrofa), Philosophical Trans. of the Royal Society of London, Vol: 164, p. 289 ff., 1874.

Parter, W. K., and Bettany, G. T. The Morphology of the Slicul, London, 1877. 


\section{Mabel Bishop}

*Rathke, H. Ueber d. Entwick. d. Arterien w. bei d. Sïugethiere ron $\mathfrak{A}$. Bogen d. Aorta ausgehen, Müller's Arch., 1843.

*Rathke, H. Untersuchungen über d. Aortenwurzein .d. Saurier, Denkschriften d. k. Akad. Wien, Bd. XIII, 1857.

Retghand and Jennings. Anatomy of the Cat, New York, 1902.

Spalteholz, Werner. Hand Atlas of Human Anatomy. Vol. II, Heart and Blood-vessels. Vol. III, Brain and Nerves, Leipzig, 1901-1903.

SpeE, F. Graf. Skeletlehre. Abt. II, Kopf, in Handbuch der Anatomie des Menschen von Karl von Bardeleben, Band I, Jena, 1896.

TANDLER, J. Zur Entwickelungsgeschichte der Kopfarterien bei den Mammalien, Morph. Jahr., Bd. XXX, 1902.

Thomson, A. On the Development of the Vascular System of the Fotus of Vertebrated Animals, Edinb. New Phil. Jour., Vol. IX, 1830-1831.

Tonge, M. Observations on the Development of the Semilunar Valves of the Aorta and Pulmonary Artery of the Heart of the Chick, Phil. Trans., CLIX, 1869.

Quain. Elements of Anatomy, Vol. I, Part I; Vol. II, Part I and II ; Vol. III, Part I, London, 1894, 1895, 1896.

Weber, Dr. Max. Die Säugetiere, Jena, 1904.

WiEdersherm, Dr. Robert. Vergleichende Anatomie der Wirbeltiere, Jena, 1906.

Wrider, H. H. Duplicate Twins and Double Monsters, The Amer. Jour. of Anatomy, Vol. III, p. 387 ff., 1904.

WrLder, H. H. Morphology of Cosmobia. The Amer. Journ. of Anatomy, Vol. VIIT, 1908 , p. 355.

Zummerana, W. Ueber ein zwischen Aorten u. Pulmonalbogen gelegenen Kiemenarterienbogen beim Kaninchen, Anat. Anzeiger, Jabrg. IV, No. 23, S. 720,1889 .

(Asterisk indicates the literature not seen by the writer.)

\section{EXPLANATION OF PLATES.}

In all $\mathbf{A}$ the right component, $B$ the left component.

In Plates V, VI, VII branches of the main arteries are indicated, but not named. 